\title{
SOBRE EL COMIENZO INOLVIDABLE DEL ACADÉMICO LUIS EDUARDO BRIONES MORALES, PREMIO NACIONAL DE CONSERVACIÓN DEL PATRIMONIO CULTURAL DE CHILE, 2012
}

\author{
Lautaro Núñez Atencio ${ }^{1}$
}

\begin{abstract}
Luis Eduardo "Lalo" Briones Morales nació en la oficina salitrera Pedro de Valdivia cuando su madre, Elba Morales Núñez, nieta de nuestro bisabuelo Francisco de Borja Núñez Loayza y de Luisa Olcay Mendoza, del cercano Valle de Quisma (bautizados entre los años 1843-1848), perfumaba los mercados salitreros con las frutas piqueñas. Mientras su padre, Alejandro, minero empedernido y comerciante, se movilizaba por todo el Desierto de Antofagasta. Lalo aprendió a caminar en el sector Resbaladero, junto a la "cocha" de Pica, y lo hizo tan bien que su andar interminable fue su mejor instrumento para sus exploraciones en el desierto tarapaqueño. Él sabía que estaba respaldado por un territorio, su espacio natural, donde ya había observado ese potencial insospechado de tantos sitios ya marcados en su mapa mental, aún embrionario. Acogió de sus ancestros tempranamente la tradición hispano-criolla junto a las raíces mestizas derivadas del componente Olcay, que nos acercó a la valoración igualitaria de ambos orígenes. Lalo podía cargar el anda de Nuestra Patrona Santa Rosa de Lima en las procesiones del Pueblo de Quisma e iniciar la celebración del Año Nuevo Aymara en su espacio hogareño de Poromita. Sin embargo, cuando lo invitaba a la festividad del santuario de la Tirana siempre tenía compromisos ineludibles... hasta que un día me confesó que muy niño se perdió allí un 16 de julio y después de varias horas recién lo encontró llorando su "mamita" ...

Se crio rodeado exclusivamente de mujeres muy emprendedoras, con sus tías y hermanas de personalidades muy respetadas y siempre rodeado de toda su familia. Nos amistamos desde los seis o siete años, y como yo era el hermano más chico entre mi familia, me entendía más con él que con mis hermanos
\end{abstract}

mayores. Entonces nos criamos como primos muy cercanos. Él vivía en mi casa cuando iba a Iquique y yo hacía lo mismo en la suya cuando viajaba a Pica, y así estuvimos juntos hasta ahora. Me enseñó a distinguir en la chacra de la tía Luisa cada clase de frutas, sus calidades, cómo se riegan, se abonan, a recoger limones en los callejones, el aseo bajo la higuera, cazar palomas cuculíes para la cena y aprender a guiñar los ojos en la cocha... Por mi parte, en las pozas de mi barrio El Morro de Iquique le enseñamos a pescar y mariscar, explorar sitios arqueológicos y caletas en el litoral, bailar en los primeros malones y, por cierto, también a guiñar los ojos en la playa Bellavista... Estos antecedentes costeros explican las convocatorias que mantuvimos después en los veranos, cuando levantábamos campamentos familiares con amigos de la infancia en caletas alejadas al sur de Iquique, donde se ponían a prueba nuestras habilidades: Lalo era recolector especializado por excelencia y el mejor en armar fogatas para cocinar en sus clásicas ollas y teteras ennegrecidas, al tanto que yo aportaba los pescados.

Toda su enseñanza primaria ocurrió en Pica. Lalo, como muchos de nuestra generación, fue un profesional que surge de las políticas educativas de Estado, de la educación pública. Nuestras familias no gastaron dinero: era gratuita. Por eso es que hace el típico recorrido: escuela primaria en Pica, Liceo de Hombres en Iquique y, por supuesto, la Universidad de Chile en Santiago. De esos tiempos recuerdo una anécdota que me parece muy premonitoria. En ese entonces viajábamos a Santiago cuando íbamos a la universidad, porque no había universidades en estas regiones. Como celebrábamos esa vez los carnavales en Pica, teníamos que subirnos en la estación Pintados al Longino, más conocido como el "pata de fierro",

$\overline{1}$ Instituto de Investigaciones Arqueológicas y Museo, Universidad Católica del Norte, San Pedro de Atacama, Chile. 
que nos llevaba hacia La Calera y de allí a Santiago. Si hay que buscar un signo que lo marcó inicialmente respecto del arte rupestre prehispánico, ocurrió en ese viaje repleto de estudiantes universitarios. Los vagones estaban llenos y sentados ambos en la pisadera, mirando extasiado esos geoglifos gigantescos Lalo me comentó acerca de sus ansias de investigarlos algún día... Lo sorprendente además fue que, una vez dentro, nuestros amigos se reían del empolvado de harina que quedaba todavía en nuestras cabezas carnavaleras... Después, en todos los veranos de vacaciones recorríamos lugares de nuestro interés exploratorio, tanto que Lalo ubicó una casa abandonada que había sido de su padre cuando tenía minas por Huatacondo, y yo hacía lo mismo con los restos mínimos del lagar de nuestro bisabuelo de Quisma...

En Santiago se acercó a la Universidad de Chile, donde estábamos sus "hermanos" Juan Varela y el suscrito, y allí se rodeó de los valores latinoamericanistas, progresistas y laicos. Inicialmente quiso ser geólogo, pero Juan le advirtió a tiempo de los requerimientos del dominio de las ciencias "duras" desde el comienzo de esa carrera, las que Lalo ciertamente aborrecía. Ingresó a la carrera de arqueología tras la revelación de su gran secreto: el arte americano. Sin embargo, las respuestas que buscaba estaban muy alejadas en ese programa y la Facultad de Bellas Artes estaba a la mano con cursos iniciales que incidían más directamente en su ideario. Después de todo, dibujaba y pintaba muy bien y un cuadro relativo al desierto aún asombra a la familia... Después de cinco años se tituló de Profesor de Estado en Artes Plásticas, tanto su tesis: "Petroglifos de Tarapacá 47: Una Contribución a la Arqueología del Norte de Chile", como el afecto y reconocimiento de sus profesores formadores, entre los que se encontraban Sergio Montesinos, Israel Roa, Gracia Barrios, Ximena Cristi, Ramón Vergara Grez y Luis Advis, entre otros memorables, lo condujeron a la valoración del arte precolombino y colonial, observado desde nuestro propio país. En Santiago vivía en casa de la tía Julia Besse, hija de Luisa Núñez Mendoza, del Resbaladero, y junto con Juan nos contactábamos para organizar el próximo verano en el norte, y de paso comentar nuestra vida universitaria.

Lo acompañé en sus estudios cuando tuve la certeza que estaba en la Facultad adecuada, rodeado de profesores que tenían una orientación americanista. Eso explica porqué Lalo tuvo una gran llegada a esa disciplina, dado su interés por el arte americano y básicamente por sus ancestros, en el arte colonial americano e indígena. Por eso su tesis de titulación se sustenta en un sitio con petroglifos de la quebrada de Tarapacá. En verdad, ya era parte del equipo que habíamos constituido allí conjuntamente con Juan Varela, y él dentro del equipo tomaba la parte del arte rupestre que dio lugar a una de sus primeras publicaciones compartidas, al tanto que dibujábamos juntos la planta del asentamiento formativo de Caserones.

Después de titularse ejerció de inmediato en Santiago, en el Liceo de Hombres $\mathrm{N}^{\circ} 6$ de San Miguel, enseñando con su particular afecto a los alumnos y su estilo de hablar en forma sencilla sobre temas de enorme complejidad, echando a correr el antiguo arte occidental con las creaciones andinas del pasado. Lo hacía en clases casi como un hermano mayor, cuando los programas ignoraban nuestro patrimonio cultural y, por otra parte, las disciplinas en torno a los ritos rupestres eran aún incipientes en Chile. Estaba en esto cuando conoce a Anita Valentin, forman familia y nacen sus hijos Viviana y Esteban. Estaba organizando recién su vida familiar cuando ocurre el golpe de Estado y se inicia la dictadura cívico-militar, y con ello las exoneraciones y las persecuciones. Dado este ambiente, me comenta que sería bueno salir de Santiago. Justamente en ese momento se abre un concurso en la Universidad de Chile sede Arica, que gana Lalo, incorporándose al Departamento de Arte, donde había también un grupo dedicado a los temas americanos. Por supuesto el curso que dictó fue dedicado al arte de nuestras raíces.

Cuando Lalo pasa a la Universidad de Tarapacá, luego que la dictadura cerrara la sede local de la Universidad de Chile, como lo hizo también en Iquique y Antofagasta, ya va marcado con un Programa Educativo. Lo que ya había analizado en la Quebrada de Tarapacá, en varios otros sitios que estaban alrededor de Pica y también en la costa y la Laguna del Huasco. Además, de lo que encontraba en la misma región de Arica, con caracteres muy propios y un potencial no estudiado del arte rupestre prehispánico y religioso colonial. Sus investigaciones se fueron extendiendo, primero desde el arte general americano a los sitios específicos con petroglifos y pictografías, y luego a los geoglifos, hasta establecer un programa de investigaciones relacionado con el arte precolombino y ese afán de poder entenderlo por dentro, no solo el dibujo o la foto, no la técnica o tipología por sí misma, sino poder captar la esencia misma de esas expresiones. Objetivos a los que no siempre los arqueólogos llegamos y concluimos, pero Lalo tenía esa tremenda capacidad de poder entender la esencia de esos mensajes, comentándolos en sus momentos de intimidad, porque esas indagaciones las mantenía siempre inconclusas. 
El rol desempeñado en la Universidad de Tarapacá en el estudio y conservación del arte rupestre y el arte religioso colonial ariqueño y tarapaqueño, apoyado por el Servicio Nacional de Turismo y un proyecto de la Organización de Estados Americanos, fue muy relevante y, por cierto, amparado en esa magnífica formación recibida en su escuela de la Universidad de Chile. En esos tiempos, cuando aún eran poco frecuentes los estudios de esta naturaleza en el norte de Chile, también dio rienda suelta a su forma tan coloquial de enseñar, que lo hizo estar siempre rodeado de cuadros jóvenes que lo consultaban. Al crearse la carrera de Antropología, aprovechando sus conocimientos, trayectoria y experiencia, se hizo cargo de las cátedras Arte Rupestre Andino y Patrimonio Natural y Cultural, las que impartió por varios años hasta su retiro de la Universidad. De todas maneras, sus mejores clases las impartía en el terreno mismo, donde se desenvolvía con más comodidad junto a sus iconos preferidos.

Hemos compartido mucho académicamente con Lalo (Briones et al. 2005; Núñez y Briones 1967, 2017, 2020, 2021 a y 2021b). Pero, quizás lo principal es que hemos estado juntos excavando los campamentos caravaneros asociados a los geoglifos de Pintados y Soronal, bajando en una caravana de aymaras desde Llica a la costa sur de Iquique en un documental de Francisco Gedda... No es necesaria la referencia solicitada y año; francamente, me cuesta hacer un recuento de en cuántos terrenos estuvimos juntos. Siempre me esperaba detrás de un geoglifo perdido. Los sentía de lejos, incluso aquellos tan borrados que solo él podía ver y admirar. ¡Ay! de aquel geoglifo que tratara de ocultarse, en donde solo él sabía que debía estar, asociado a una ruta determinada, en esos pasos obligados, donde indicaba: "aquí debe estar" y, de verdad, allí estaba. Aunque me decía que envidiaba la mirada de los cóndores... o a veces expresaba que le gustaría ser lagarto para verlos bien de cerca sin dejar huellas... Yo le replicaba que alimentaba a los pájaros en su casa-huerto de Poromita porque solo ellos tendrían la posibilidad de observar a sus queridos geoglifos que rodean Pica, sin perturbarlos, a la espera de su nuevo proyecto de conservación.

Sus colegas y alumnos saben los detalles de su vida académica en Arica, son los que más conocen de su vida cotidiana, su carrera académica y su asombrosa estatura intelectual y personal, de modo que aquí debiese terminar mi relato y dejar que comience el de ellos (se pueden mantener también mis propios aportes en Núñez 2011 y 2015). Sin embargo, no puedo dejar de mencionar temas recientes, relacionados con mis últimos encuentros con Lalo.
Todo el mes de febrero del año 2020, cuando comienza la pandemia, estuve en la cabaña que también tengo en Poromita y aprovechamos de avanzar en los temas comunes y pendientes (entre ellas las publicaciones que se encuentran al final de las Referencias Citadas, en prensa, enviadas y en preparación). En esa oportunidad me comentó sus nuevas preguntas y con un mapa a la vista me señaló nuevas rutas costeras, paralelas a la Cordillera de la Costa, con sus respectivas bajadas al litoral, todas de data prehispánica, situadas al sur de Arica y asociadas algunas con petroglifos. Aparte, en otro mapa me indicó la ubicación de senderos peatonales prehispánicos que unían asentamientos entre valles. No se trataba de las rutas principales caravaneras, como las asociadas a geoglifos, sino aquellas entre pueblos con dos o tres bloques petrografiados. No era la red clásica en rastrillo que habíamos estudiado, se trataba de una micro trama vial que él estaba descubriendo entre pequeños asentamientos prehispánicos y actuales.

En eso estaba cuando me dice que una vez que termináramos el artículo sobre un sitio con geoglifos históricos, debería apoyarlo en la preparación de una monografía sobre los geoglifos de Cerros Pintados. Me explicó que el libro sobre Pintados sería importante, ya que había demasiada información en los campamentos, desde todos los puntos de vista, relativa justamente a los geoglifos. Con una metáfora muy de él, me señaló que las rutas transdesérticas se transformaron en valles para orientar las conexiones con la costa...; y para bromearlo le dije que sí, pero con poca agua... Recuerdo haberle comentado que no olvidara que apenas pasara la pandemia también teníamos que excavar, junto con los colegas de Arica y San Pedro, un sitio arcaico temprano en el borde del salar de Pintados, patrocinados por la National Geographic Society. Seguíamos dándonos tantas tareas, pendientes y nuevas, que decidimos parar la conversación para revisar mejor un inmenso cuadro genealógico de la familia y una secuencia de fotos familiares de inicios del siglo XIX a la actualidad, recién puesta en la pared de mi cabaña.

Del relato que he hecho de Lalo se desprende cómo un joven de un oasis, apoyado por la educación pública, logra ser el primero en su familia en alcanzar la Universidad, que por su vocación y gracias a los excelentes profesores que tuvo en Santiago logra descubrir cuál es su gran tema para sus futuras investigaciones y, finalmente, opta por su "nortinidad" para quedarse donde debía estar, rodeado en Arica con colegas que lo acogieron con mucha ciencia y cariño. Este es un gran mensaje para los jóvenes de 
hoy, los que en el marco de sus investigaciones iniciales pueden tenerlo como un gran referente, porque se puede llegar a ser lo que Lalo fue, en la medida que se abrace la ciencia con entrega total y trasmisión afectuosa a la vez, incluyendo los valores que vienen antes de nosotros, como son los aportes de los estudios previos, y cómo contribuir al tejido intercultural de nuestro tiempo junto a los pueblos originarios. Ese arte mayor de sacar afuera lo que sabe, lo investigado, con palabras tan sencillas y comprensibles, sin conclusiones grabadas en rocas, sino en permanente rehacer... Cuántos "Lalos" pueden escuchar estos relatos y ver que se puede, en la medida que tengan esa fuerza para sentir el territorio y sus gentes, las de antes y de ahora, hacerles las preguntas precisas desde sus disciplinas y llegar a saber que para encarar la espiritualidad que encierra el arte rupestre se requiere leerlo desde las analíticas y sus propias espiritualidades, sumando, por cierto, aquellas sabidurías que aun están sumergidas entre nuestros pueblos originarios.

No puedo dejar tampoco de mencionar que en estos mismos momentos hay colegas del Museo Arqueológico Municipal de Pica que han escuchado y vivido este relato, pues también compartieron toda la fuerza que tenía Lalo para seguir sus idearios, residiendo en su casa en Poromita y como "Hijo Ilustre de Pica", para entregar su conocimiento y su tremenda sensibilidad social. Me permito también entregar mi gran afecto a su familia, representada por sus hermanas Mirta y Orieta, sus sobrinos, y sobre todo, a la tía Elba, su

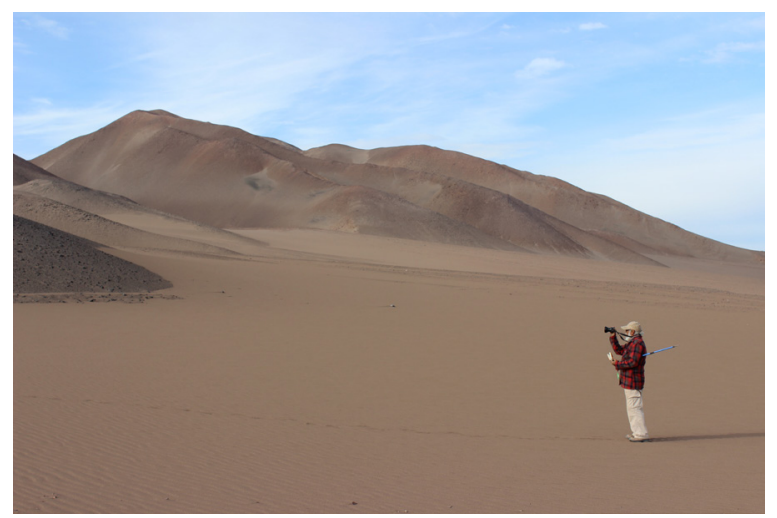

Lalo frente a los geoglifos de Challacollo. madre, que, con más de cien años, vive esperándolo... También a Anita, su compañera y a sus hijos, Viviana, una prestigiosa etnohistoriadora, formada precisamente en su Universidad de Tarapacá y, por supuesto, a su hijo Esteban, el geólogo por excelencia, quienes también recogieron ese espíritu de Lalo a través de disciplinas que le fueron muy cercanas.

Sigo viendo a Lalo cuando riega, "conversar" con el agua, sus pájaros, sus naranjos que compiten con mis guayabos, su perro vigilante y los árboles adolescentes tan bien criados, uno a uno, aprovechando que se han ido sus visitas, aquellas que llegan a compartir con el maestro. Definitivamente, sus días parecen todavía ser tan cortos como largos los sueños que lo conducen siempre a ese geoglifo, al patrimonio cultural rupestre siempre frágil, a un recuerdo imborrable, hasta que apaga su radio que tiene permanentemente encendida, para abrir su libro favorito. Sigo escuchando su silbido, que me indica que un nuevo día ha comenzado... Estoy terminando un manuscrito que preparamos con Lalo y cuando tengo alguna duda tomo inconscientemente el celular para llamarlo y aclararla, porque todavía siento que está dando vueltas por ahí, persiguiendo un geoglifo rebelde... De hecho, se despidió con su ropa de terreno y él sabe que lo encontraremos entre sus geoglifos de Pintados, escuchándole con su particular lenguaje onomatopéyico esos relatos que entre nosotros eran interminables y así lo seguirán siendo, como ocurre entre verdaderos compadres, en estos momentos en que todavía continúa a mi lado...

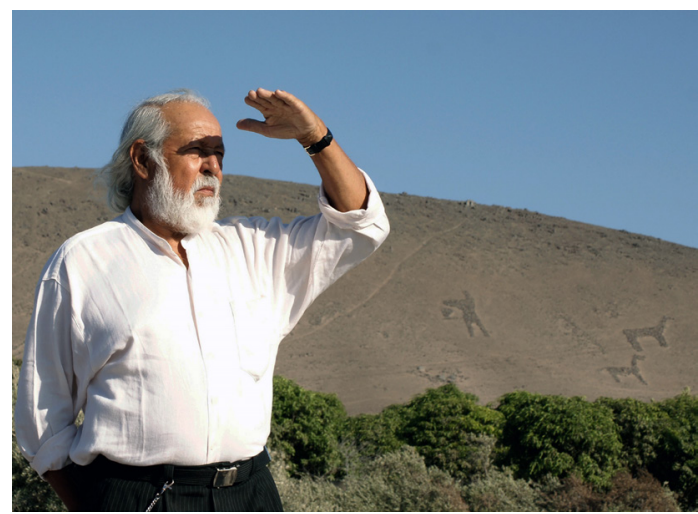

En Cerro Sombrero, Valle de Azapa, Arica. 


\section{Referencias Citadas}

Briones, L., L. Núñez y V. Standen 2005. Geoglifos y tráfico prehispánico de caravanas de llamas en el Desierto de Atacama (Norte de Chile). Chungara Revista Chilena de Antropología 36 (2):195-223.

Núñez. L. 2011. Prólogo. En Conservación y Restauración de Geoglifos en el Norte de Chile, editado por?? L. Briones y P. Casanova, pp. 9-12. Centro de Investigaciones del Hombre en el Desierto (CIHDE) y Consejo Nacional de la Cultura y las Artes (CNCA), Arica.

Núñez, L. 2015. Homenaje al Profesor Investigador Luis Briones Morales. Actas del XIX Congreso Nacional de Arqueología Chilena, pp. 33-39. Universidad de Tarapacá y Sociedad Chilena de Arqueología, Arica.

Núñez, L. y L. Briones 1967. Petroglifos del sitio Tarapacá 47 (Provincia de Tarapacá). Estudios Arqueológicos 3-4:43-84.
Núñez, L. y L. Briones 2017 Tráfico e interacción entre el oasis de Pica y la costa arreica en el desierto tarapaqueño (norte de Chile). Estudios Atacameños 56:133-161.

Núñez, L. y L. Briones 2020. Interacción entre caravaneros y costeños en el desierto de Atacama. El puerto de tráfico del salar Soronal (Periodo Intermedio Tardío). En Los Desafios del Tiempo, el Espacio y la Memoria. Ensayos en Homenaje a Peter Kaulicke, editado por R. Vega-Centeno y J. Dulanto, pp. 261-308. Fondo Editorial Pontificia Universidad Católica del Perú, Lima.

Núñez, L. y L. Briones 2021a. Valoración de las pinturas de Chomache en la costa árida del Desierto de Atacama (Norte de Chile). Chungara Revista Chilena de Antropología 53 (2):261-282.

Núñez, L. y L. Briones 2021b. Intersite locations of prehistoric caravan traffic in the core of the Atacama Desert, Northern Chile. En Caravans in Socio-Cultural Perspective: Past and Present, editado por P.B. Clarkson y C.M. Santoro. Routledge, Londres. En prensa. 
